\title{
Pandemic Loss
}

\author{
Jeffrey D. Kravetz, $M D^{1,2}$ (D) \\ Check for \\ 'Department of Internal Medicine, Yale University School of MedicineNew Haven, CT, USA; ${ }^{2}$ Veterans Affairs Connecticut Health Care System \\ (1ACSL) West Haven, CT, USA.
}

$\mathrm{J}$ Gen Intern Med 35(8):2437-8

DOI: $10.1007 / \mathrm{s} 11606-020-05879-\mathrm{y}$

(c) Society of General Internal Medicine (This is a U.S. government work and not under copyright protection in the U.S.; foreign copyright protection may apply) 2020

${ }^{66} 1$ m sorry to have to tell you, but he expired this morning." Though I was prepared for this, these words shook me to my core. Two weeks before, my father was a vibrant 75 -year-old playing racquetball and tennis with his friends. He was the glue of our family and the most optimistic and kind person you could ever meet. Now he was gone, another statistic in the ongoing count of deaths attributed to COVID-19 and its complications. Grieving his sudden loss was difficult enough; doing so in a pandemic has been cruel and isolating. We mourned as a family on zoom but remained separated from each other, unable to hug our mother who was quarantined while also recovering from COVID-19. I stood next to my mother at the funeral, wearing an N-95 mask, face shield, gloves, and gown, just to be able to hold her hand and avoid her standing completely alone.

Seven days after his death, I returned to my work as a primary care provider in a leadership position tasked to help manage our response to the ongoing pandemic. Meeting after meeting about how to triage calls and manage walk-ins with symptoms that might or might not be attributable to coronavirus. Call after call about how to triage our medical staff to provide inpatient care for our growing census of patients admitted with COVID-19. Template after template outlining the proper way to follow outpatients who tested positive for COVID-19, but are being monitored at home. Phone call after phone call to patients who either had tested positive for COVID-19 or wanted to be tested. As the sole person in my family with a medical background, I had just done all of this with my dad. I monitored his symptoms from home 2-3 times/day, followed his pulse oximetry, and ultimately decided to have him taken by ambulance to the emergency room. I worked with the inpatient medical team to have him treated with the best, albeit completely unproven, therapies available. I

Received April 13, 2020

Accepted April 28, 2020

Published online May 14, 2020 spoke with my dad multiple times per day until he no longer could speak after being intubated. I wore 2 hats for the duration of his illness: one as the medical provider following his course and one as his son translating this data for my family while slowly feeling him slip away to this awful illness.

I continued to try to function in my role as Associate Primary Care Service Line Manager and Firm Chief until I no longer could do so. Benign email titles such as "preparedness of the worst" started to irritate me. What could be worse than what I have been through? Comments from leadership about optimism surrounding possible flattening of the curve angered me. Emails about stress related to teleworking issues and technological hurdles annoyed me. During one meeting describing the clinical course of COVID-19, a tidal wave of emotions overtook me. Palpitations, sweating, and overwhelming anxiety forced me to sign out and immediately seek fresh air. It was then that I realized that the constant discussion of the illness that took my dad way too soon was triggering an intense, unpredictable, and disabling anxiety that I was continuing to feed into by being actively involved in these discussions. I needed to step away. I needed to manage something other than COVID-19. I needed to breathe.

As the current pandemic evolves over the next few months, more and more healthcare providers will be facing the same issue that I am trying to manage. More front-line providers and nurses will lose loved ones in this pandemic and will need to step away to grieve as best as they can. It is virtually impossible to expect our healthcare providers to continue to manage patients dying of the same viral illness that took away their family member. The constant reliving of recent losses will cause some healthcare providers to be unable to provide the care that these patients deserve. Providers need time away to grieve and should only return when they are ready.

In order to help with this, we must realize that we are all in this fight together but that healthcare is not all about coronavirus. Patients still have congestive heart failure, still have diabetes, and still have asthma. Patients still have depression, anxiety, and post-traumatic stress disorder. It is imperative for leadership in healthcare organizations to reach out to grieving providers and not throw them back into the same fire that just burned them. There is plenty of other work to do in this time to keep our patient care population safe while trying to provide care virtually. Redistributing this work to grieving providers who are ready to return to work will allow for better care for 
our patient population while removing them from the constant barrage of COVID-19 issues. If at all possible, removing inpatient providers and nurses from COVID wards is necessary to allow for healing to slowly occur. In time, these mourning providers and nurses will need to say when they are ready to return to the care of patients with COVID-19. Expecting them to do so immediately upon returning from grieving creates an untenable situation and will create a constant cycle of triggering and anxiety that will continue to impede the healing process, while possibly leading to suboptimal care of patients with COVID-19.

Corresponding Author: Jeffrey D. Kravetz, MD; Veterans Affairs Connecticut Health Care System (1ACSL) West Haven, CT, USA (e-mail: Jeffrey.Kravetz@va.gov).

Publisher's Note: Springer Nature remains neutral with regard to jurisdictional claims in published maps and institutional affiliations. 